\title{
Effect of structural heterogeneity water-coal fuel conditions and characteristics of ignition
}

\author{
S.V. Syrodoy ${ }^{1, a}$, V.V. Salomatov ${ }^{2}$, Ph.D. and N.Y. Gutareva ${ }^{1}$, Ph.D. \\ ${ }^{1}$ Tomsk Polytechnic University, Tomsk, Russia \\ ${ }^{2}$ Institute of Thermophysics. S.S. Kutateladze CO RAN, Novosibirsk, Russia
}

\begin{abstract}
The problem of the particle ignition of coal-water fuel (CWF) with a joint course of the main processes of a thermal (thermal conductivity, evaporation, filtration heat and mass transfer, thermal decomposition of the organic part) has been solved. According to the results of numerical simulation ways of describing the extent of the influence of the thermophysical properties on the characteristics and conditions of ignition WCF have been set.
\end{abstract}

\section{Introduction}

Ignition processes are an important element of many technologies of power system, have been studied recently quite extensively both experimentally [1-3] and theoretically [4-7]. In particular, physical and mathematical models of ignition have been developed in a local heating of the liquid $[3,6]$ and solid fuels $[1,2,4,5,7]$. Two approaches [8-11] have been formulated to the modeling process and the ignition of coal-water fuel (CWF). The models $[8,9]$ and $[10,11]$ are different from the description in time complex physical and chemical transformations preceding the direct ignition WCF. Description of co-occurring processes of thermal conductivity, evaporation of water, the thermal decomposition of the organic part of coal, filtration of water vapor and gaseous pyrolysis products to the heated surface, the thermochemical interaction products of physical and chemical transformations of the environment with the oxidant in the model $[10,11]$ create the conditions for more complete, compared to [8,9], prognosis of conditions and the ignition characteristics of individual particles of coal-water fuel.

When solving problems $[10,11]$ the structural features of coal-water fuel particles have not been taken into account caused by mixing water and coals of different fields. At the same time it is known [12] that the structural features of condensed materials in many cases have a significant effect on the intensity of the heat and mass transfer processes in the induction period as a consequence of the change in thermal conductivity and heat capacity.

The aim of the work is to study the theoretical impact of the thermophysical properties of coal on the regularities of coal-water fuel particle ignition.

\footnotetext{
${ }^{a}$ Corresponding author: ssyrodoy@yandex.ru.ru
}

This is an Open Access article distributed under the terms of the Creative Commons Attribution License 4.0, which permits unrestricted use, distribution, and reproduction in any medium, provided the original work is properly cited. 


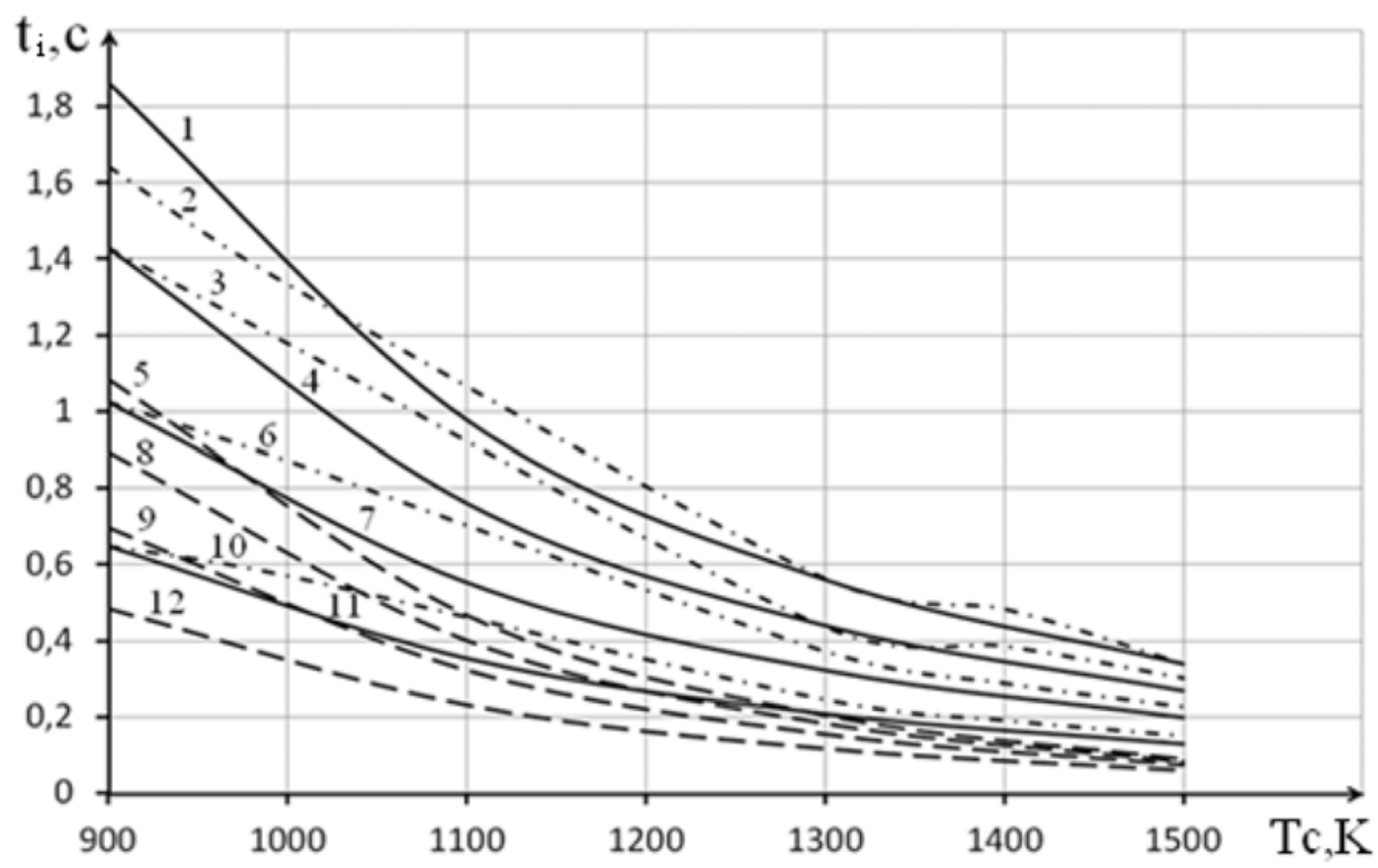

Figure 1. The dependence of the ignition delay time of the ambient temperature at various representations of the thermophysical properties of the particle diameter WCF: $1,2,5-\mathrm{d}=1 \cdot 10^{-3} \mathrm{~m} ; 3,4,8-\mathrm{d}=0,8 \cdot 10^{-3} \mathrm{~m} ; 6,7$, $9-\mathrm{d}=0,6 \cdot 10^{-3} \mathrm{~m} ; 10,11,12-\mathrm{d}=0,4 \cdot 10^{-3} \mathrm{~m} .1,4,7,11$-thermophysical properties of the corresponding homogeneous coal; 2,3,6,10-thermophysical properties were determined based on the mass fractions of the fuel components $(\varphi) ; 5,8,9,12$-thermophysical properties were calculated from the model $[13,14]$.

\section{Statement of the problem and the solution method}

The problem of ignition coal-water fuel particles in the high temperature $(\mathrm{T}>900 \mathrm{~K})$ gas atmosphere has been solved. The physical model of the investigated process generally matches with the models $[10,11]$. The difference lies in the fact that when the problem is considered in view of the particle WCF heterogeneity of its structure. The system of equations and boundary conditions describing the processes of heat and mass transfer, evaporation of water, filtration of water vapor, the chemical interaction between the latter and the gaseous products of thermal decomposition of the organic portion of solid fuels with carbon degradation products, mainly corresponds to the mathematical model [10, 11]. Objective ignition particle coal-water fuel has been solved by the method described in detail in [10].

The consideration of complex fuel compositions WCF entails problems related to the definition of effective thermophysical characteristics affecting the ignition conditions. The following methodology has been used in order to evaluate the impact of different models of the thermophysical properties of the dynamics of ignition WCF.

In the first variant, formulations of the problem and the thermal characteristics of the wet "dehydrated" part of the fuel have been calculated taking into account the volume fractions of the components:

$$
\begin{array}{lll}
\lambda_{1}=\varphi_{3} \lambda_{3}+\varphi_{4} \lambda_{4} & \mathrm{Cp}_{1}=\varphi_{3} \mathrm{Cp}_{3}+\varphi_{4} \mathrm{Cp}_{4} & \rho_{1}=\varphi_{3} \rho_{3}+\varphi_{4} \rho_{4} \\
\lambda_{2}=\varphi_{3} \lambda_{3}+\varphi_{5} \lambda_{5} & \mathrm{Cp}_{2}=\varphi_{3} \mathrm{Cp}_{3}+\varphi_{5} \mathrm{Cp}_{5} \quad \rho_{2}=\varphi_{3} \rho_{3}+\varphi_{5} \rho_{5}
\end{array}
$$




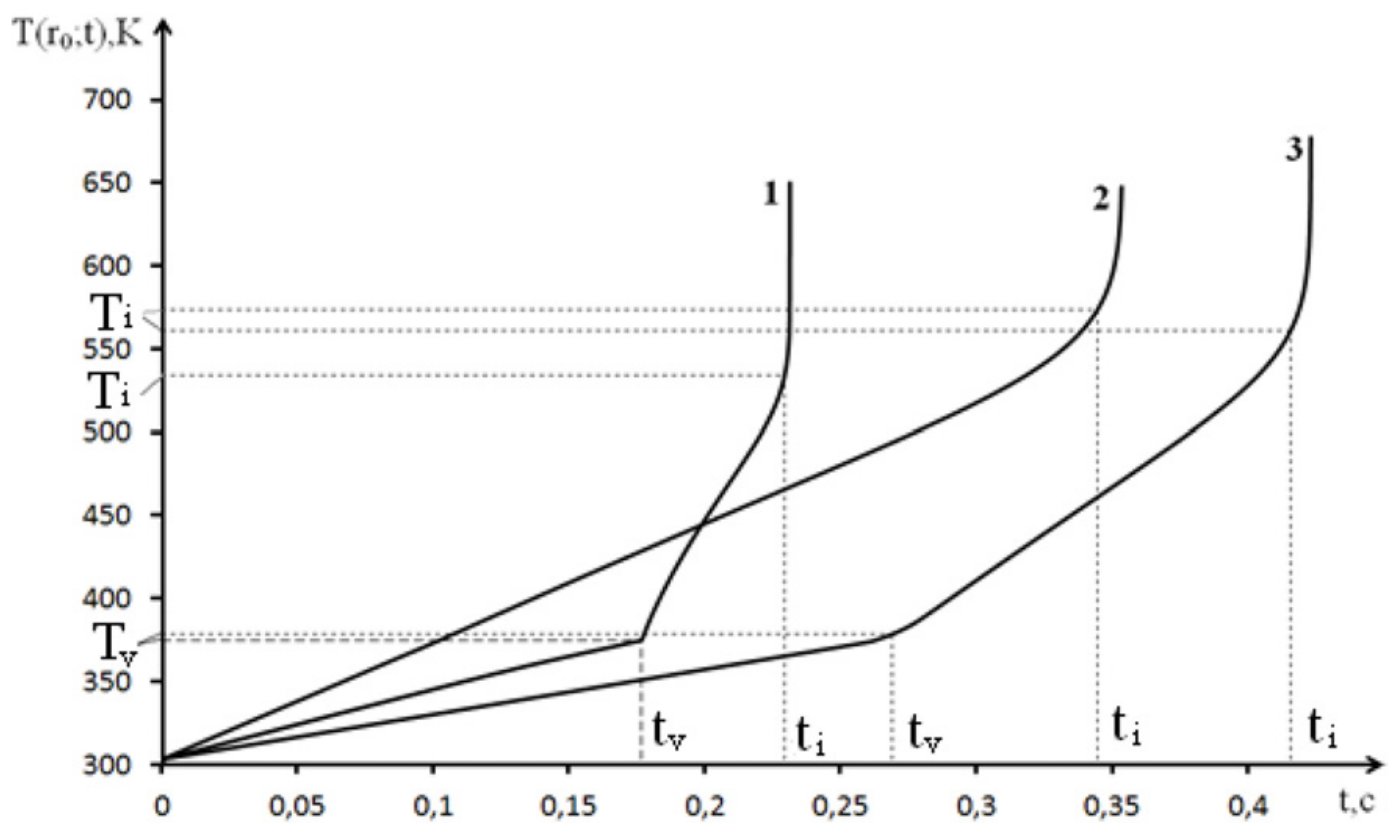

Figure 2. Dependence of the particle surface temperature $\mathrm{T}\left(\mathrm{r}_{0} ; \mathrm{t}\right)$ from the time the ignition process td particle diameter $\mathrm{d}=0.4 \cdot 10^{-3} \mathrm{~m}$ in the environment with a temperature $\mathrm{Tc}=1100 \mathrm{~K}$ in different variants of notions of thermophysical properties of WCF: 1- thermophysical properties have been calculated from the model [13, 14]; 2thermophysical properties of the corresponding homogeneous coal; 3 thermophysical properties were determined based on the mass fractions of the fuel components $(\varphi)$.

where: $\varphi$ - volume fraction of the respective component of fuel: 1 - initial (wet) part of WCF; 2 - "dehydrated" layer of WCF; 3 - water; 4 - coal; 5 - air.

The second model is based on the results of the studies $[13,14]$. The thermophysical properties have been determined from the WCF scheme coal-water composition.

In the third variant of the model, the thermal characteristics have been made by the adequate relevant characteristics of the base material (coal).

\section{Results and discussion}

As a result of numerical simulation, ignition delay times, depending on the ambient temperature for particles of different diameters (Fig. 1) have been set. It is seen that with increasing ambient temperature $\left(\mathrm{T}_{\mathrm{c}}\right)$ decreases the ignition delay time td. It may be noted that the ignition delay times are significantly different for different models of thermophysical properties coal-water fuel. Since particles WCF, thermal characteristic of which have been calculated according to the scheme [13, 14], are ignited almost 2 times faster than the particles, thermal properties have been taken to be the characteristics of the coal fuel. The ignition delay times of the particles, the properties of which have been determined from the ratio of the equity of the system "water-coal" $[10,11]$, are in the range between the values of $t_{3}$, obtained by the above two basic variants.

The dependence of the surface temperature of the particles of coal-water fuel from time to time (until ignition WCF) has been shown in Fig. 2 for the three variants of ideas about the thermophysical properties of the particles WCF. The characteristic regions can be distinguished separated inflection point $\left(t_{v} ; T_{v}\right)$ on the two curves. Changing the slope of the curve 1 (Fig. 2.) is the formation of "dehydrated" fuel layer with high thermal resistance. For this reason, the surface temperature rise happens much faster. 


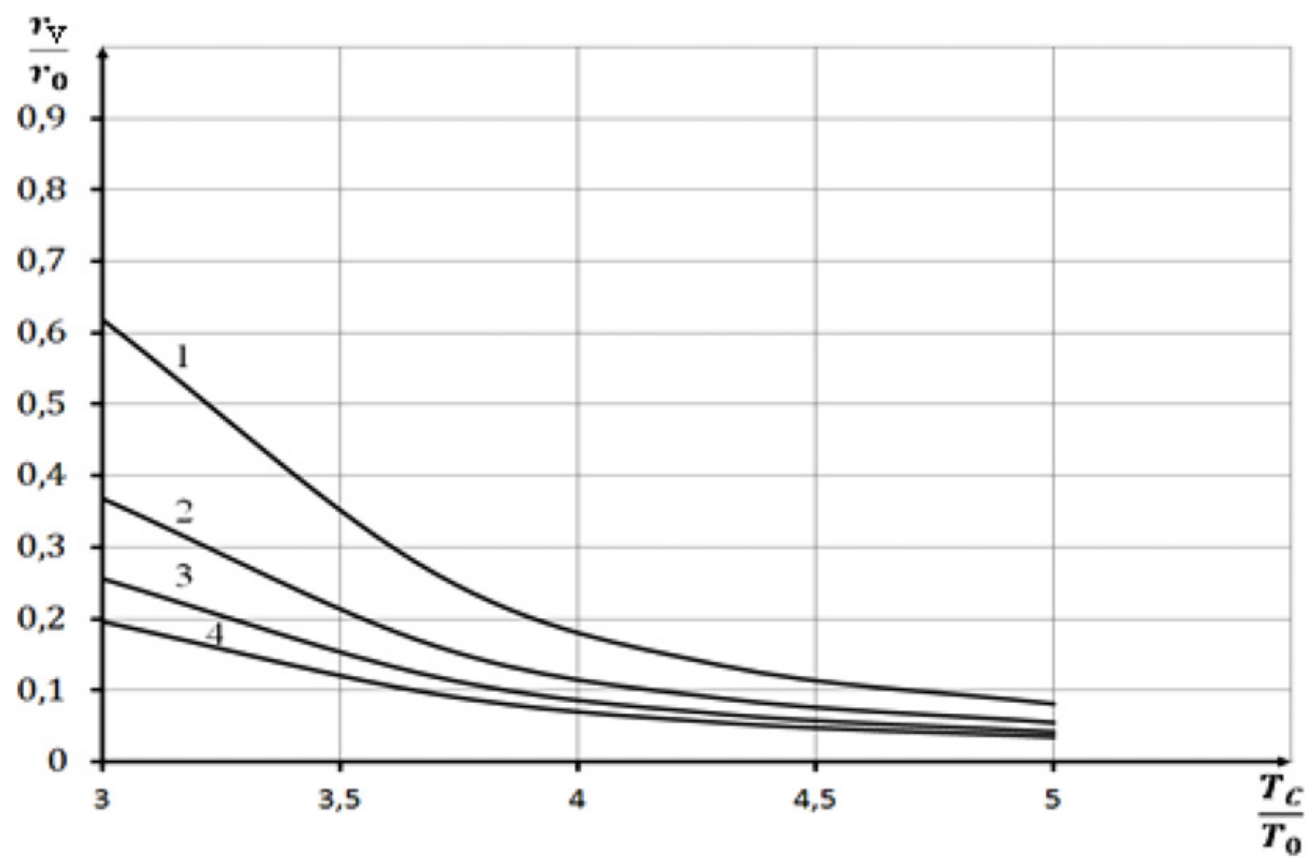

Figure 3. Relative penetration depth of the evaporation front at the moment of ignition of coal-water particles, thermal properties are determined from the procedure [13, 14]. Where: $r_{v}$ - radius of the evaporation front, $\mathrm{m} ; \mathrm{r}_{0}$-particle radius, $\mathrm{m} ; \mathrm{T}_{0}$ the temperature of the particle at the initial time $(\mathrm{t}=0), \mathrm{K} ; 1-\mathrm{d}=0,4 \cdot 10^{-3} \mathrm{~m} ; 2$ $\mathrm{d}=0,6 \cdot 10^{-3} \mathrm{~m} ; 3-\mathrm{d}=0,8 \cdot 10^{-3} \mathrm{~m} ; 4-\mathrm{d}=1 \cdot 10^{-3} \mathrm{~m}$.

For the curve 3 (Fig. 2), the inflection point characterizes time of completion of the dripping particles. The second section (to the point $\left(\mathrm{t}_{\mathrm{i}} ; \mathrm{T}_{\mathrm{i}}\right)$ ) characterizes the inert warm dry coal particles. Due to the high thermal conductivity porous carbon agglomerate latter is substantially lower compared to the "moisture saturation" particle. As a result, the temperature rises much more rapidly.

The relative penetration depth of the evaporation front at the time of ignition of the particles has been shown in Fig. 3, the thermal properties of which have been calculated by the formula [13, 14].

Found that in this case the particle ignites even before all the moisture evaporates. It may be noted that when the ambient temperature decreases the penetration depth of the evaporation front into the particle increases.

According to the results of the numerical analysis, we can conclude that when the ignition coal-water fuel particles, the model plays an important role describing the thermal properties of the CWF. In the case of thermal characteristics, considered with regard to the real structure of coal-water composition $[13,14]$, ignition WCF particles is much faster (2-2.5 times) than in the thermal characteristics corresponding mono coal fuel.

Water coal particles, thermal properties of which have been determined by the scheme [13, 14], ignite even before all the moisture evaporates (due to the high thermal resistance). Therefore, the duration of combustion processes and particle WCF pulverized fuel will significantly differ.

\section{References}

[1] Zaharevich A.V. Ignition model fuel compositions single mixed, heated up to high temperatures particle./A.V. Zaharevich V.T. Kuznetsov, G.V. Kuznetsov, V.I. Maksimov/Combust, 2008. 44. No. 5. - P. 54-57 
[2] Zaharevich A.V. The influence of experimental conditions on the ignition characteristics of the dispersed wood. A.V. Zaharevich/Engineering Physics, 2014. 87. No. 1. - P. 93-97

[3] Zaharevich A.V. Influence of conditions of heat transfer characteristic Stick ignition of liquid fuel/G.V. Kuznetsov, A.V. Zaharevich, N.S. Pups/Chemical and Petroleum Engineering, 2014. No. 7. - P. 9-12

[4] Kuznetsov G.V. Ignition of condensed matter "hot" particles./G.V. Kuznetsov, G.Y. Mamontov, G.V. Taratushkin/Chemical Physics, 2004. 23. No. 23. - P. 67-72

[5] Kuznetsov G.V. Numerical simulation of ignition of condensed matter at high temperature particle./G.V. Kuznetsov, G.Y. Mamontov, G.V. Taratushkin/40, 2004. No. 1. - P. 78-85

[6] Vysokomornaya O.V. Modeling ignition of liquid fuel local heating source in a burning liquid/G.V. Kuznetsov, P.A. Strizhak, O.V. Vysokomornaya/Chemical Physics., 2011. 30. No. 8. - P. 62-67

[7] Glushko D.O. Numerical simulation of solid-state ignition metallized condensed matter at high temperature particle./D.O. Glushko G.V., Kuznetsov, P.A. Strizhak,/Chemical Physics. 30, 2011. No. 12. - P. 35

[8] Salomatov V.V. Theoretical study of the combustion of coal-water fuel droplet./Salomatov V.V., Kravchenko I.V./Part 1. Heating step//Combustion and plasma chemistry, 2007. 5, no. 3 - P. 178188

[9] Salomatov V.V. Theoretical study of the combustion of coal-water fuel droplet./Salomatov V.V., Kravchenko I.V./CH.II. Stage evaporation//Combustion and plasma chemistry, 2007. 5, no. 3 P. 189-197

[10] Salomatov V.V., Syrodoy S.V. and Gutareva N.Y. Modelling of heat and mass transfer to solve the problem of particle ignition water-coal fuel//2014 IOP Conferense Series.: Materials Science Engineering 66012040

[11] Salomatov V.V., Syrodoy S.V. and Gutareva N.Y. Concentration organic components in the hydrocarbon fuel particles conditions and characteristic of ignition.//EPJ Web of Conferences 76, 01018 (2014)

[12] Kuznetsov G.V. Mathematical modeling of thermal and thermochemical processes during combustion of intumescent coatings og nezaschitnyh./VL. Fears, A.N. Garashchenko G.V. Kuznetsov, V.P. Rudzinskii/Combust, 2001. 37. No. 2. - P. 63-73

[13] Chudnovsky A.F. Thermal characteristics of dispersed materials. - M .: Fizmatlit, 1962. - 456 p.

[14] Dulnev G.N. Zarichnyak Y.P. The thermal conductivity of the mixtures and composite materials. - L.: Energy, 1974. - 264 p. 